\title{
Avaliação física e dos níveis séricos de cortisol de bezerros neonatos da raça Nelore, nascidos de partos normais e auxiliados ${ }^{1}$
}

\author{
Everton R.F. Gasparelli3 ${ }^{3}$, Diogo G. Camargo ${ }^{3}$, Rodrigo Yanaka ${ }^{3}$, Luiz C.N. \\ Mendes $^{2}$, Juliana R. Peiró ${ }^{2}$, Fernanda Bovino ${ }^{3}$, Sílvia H.V. Perri \\ e Francisco L.F. Feitosa ${ }^{2^{*}}$
}

\begin{abstract}
Gasparelli E.R.F., Camargo D.G., Yanaka R., Mendes L.C.N, Peiró J.R., Bovino F., Perri S.H.V. \& Feitosa F.L.F. 2009. [Physical and serum cortisol levels evaluation of Nelore newborn calves born by normal and laborious parturition.] Avaliação física e dos níveis séricos de cortisol de bezerros neonatos da raça Nelore, nascidos de partos normais e auxiliados. Pesquisa Veterinária Brasileira 29(10):823-828. Curso de Medicina Veterinária, Universidade Estadual Paulista, Campus de Araçatuba, Rua Clóvis Pestana 793, Araçatuba, SP 16050-680, Brazil. E-mail: leydsonf@fmva.unesp.br

The purpose of present study was to evaluate the vitality and the serum levels of cortisol from newborn calves by normal and laborious deliveries, and to obtain the distocia register in Nelore embryo recipient cows. Three hundred ten calves were evaluated. The register of 38 dystocic calvings (38/310) and 8 abortions (8/310) were observed. In newborn animals the morbity and mortality rates were $77.93 \%$ and $3.44 \%$, respectively. Calves born after long dystocic calving, lasting 4-6 hours, showed the highest mean values of respiratory frequency and serum cortisol levels. Animals born after laborious calving presented higher rectal temperature than those born at normal calving. The APGAR score showed that $90 \%$ calves had signs of dullness independent of parturition type.
\end{abstract}

INDEX TERMS: Calf, calving, cortisol, score APGAR.

RESUMO.- O presente trabalho visou avaliar a vitalidade e os níveis séricos de cortisol de bezerros neonatos, nascidos de partos eutócicos e auxiliados, bem como determinar os índices de partos distócicos em vacas receptoras de embriões nelores. Cerca de 310 bezerros foram avaliados. Observou-se a ocorrência de 38 partos distócicos (38/310) e de oito abortos (8/310). Os bezerros nascidos de partos distócicos mais duradouros, entre quatro e seis horas, apresentaram os maiores valores médios de frequência respiratória e dos níveis séricos de cortisol. A temperatura retal foi mais elevada em animais nascidos de partos laboriosos do que naqueles nascidos de partos

\footnotetext{
${ }^{1}$ Recebido em 31 de março de 2009.

Aceito para publicação em 30 de junho de 2009.

2 Docente do Curso de Medicina Veterinária da Unesp, Campus de Araçatuba, Rua Clóvis Pestana 793, Araçatuba, SP 16050-680, Brasil. *Autor para correspondência: leydsonf@fmva.unesp.br

${ }^{3}$ Pós-graduando do Curso de Ciência Animal, Área de Fisiopatologia Médica e Cirúrgica, Curso de Medicina Veterinária da Unesp-Araçatuba, SP.
}

normais. As taxas de morbidade e mortalidade em animais neonatos nelores foram de $77,93 \%$ e $3,44 \%$, respectivamente. $O$ emprego do escore APGAR, ao nascimento, demonstrou que $90 \%$ dos bezerros apresentavamse deprimidos, independente do tipo de nascimento.

TERMOS DE INDEXAÇÃO: Bezerro, parto, cortisol, escore APGAR.

\section{INTRODUÇÃO}

Após o nascimento, o recém-nascido necessita, para a sua sobrevivência, de intensas mudanças nos padrões respiratório e circulatório. A avaliação do neonato, por si, é de grande relevância, por propiciar a observação de indícios ou pistas de possíveis sinais clínicos de infecções sistêmicas, de alterações localizadas e/ou adquiridas, e da existência de dispnéia (Smith 2002).

A mortalidade de bezerros é a segunda principal causa de perda econômica da criação de bovinos de corte nos Estados Unidos, sendo superada apenas pelos prejuízos causados pelas falhas de manejo reprodutivo 
(Kasaki \& Wikse 1994). Em um estudo realizado com bezerros de corte, constatou-se, que $69 \%$ de todas as mortes observadas, entre o nascimento e o desmame, ocorriam às 96 horas após o nascimento, em decorrência de partos distócicos (Patterson et al. 1987).

O processo adaptativo, ao meio extra-uterino, é dependente da ativação do eixo hipotálamo-hipófise-adrenal, sendo mediado, principalmente, pelo cortisol, um potente estimulador do metabolismo (Wood 1999). Porém, o mesmo pode ser suprimido nos casos de parto distócico, devido à possibilidade de ocorrência da síndrome asfixia/hipóxia neonatal (Ray et al. 1972). Níveis mais altos que o normal de cortisol parecem estar intimamente relacionados com visíveis sinais de sofrimento (Lefcourt \& Elsasser 1995).

O parto distócico, também denominado de laborioso, trabalhoso ou anormal, pode ser de causa materna ou fetal. A incompatibilidade entre a pelve da mãe e o tamanho do feto (IPF) é a mais importante causa de distocia (Andersen et al. 1993). A IPF pode ocorrer como resultado do maior tamanho do feto, do menor diâmetro pélvico da mãe, ou de ambos. Os distúrbios hormonais, em vacas, causados por baixas concentrações de estrógenos, também são mencionados (Osinga 1978).

Peixer et al. (2000) destacaram o alto peso dos bezerros ao nascer, a gestação prolongada, o aumento nas taxas de abortamento, o aumento da mortalidade perinatal e a maior incidência de anomalias congênitas, como as principais complicações de prenhezes de embriões fertilizados in vitro.

Segundo Silva \& Gondim (1971), além da temperatura ambiente, os valores da frequência cardíaca dependem de inúmeros fatores, tais como a idade, individualidade, temperamento e o grau de excitação do animal. A magnitude das alterações é variável, pois as respostas ao estresse são diferentes, mesmo quando animais da mesma raça, são comparados (Kelly 1976).

Durante o parto laborioso, ocorre diminuição da frequência cardíaca fetal (Jonker et al. 1996). Os animais recémnascidos tornam-se hipóxicos, desenvolvendo acidose respiratória e metabolismo anaeróbico, que tendem a normalizar-se durante as primeiras 24 horas de vida (Lisboa et al. 2002).

Desvios marcantes da temperatura corpórea devem ser levados em consideração, já que podem ser indicativos de processos patológicos. Os neonatos têm o centro termorregulador ainda não completamente desenvolvido e, por isso, frequentemente apresentam temperatura corpórea de $0,5^{\circ} \mathrm{C}$ a $1,0^{\circ} \mathrm{C}$ mais elevada que os animais adultos, situando-se entre $39,0^{\circ} \mathrm{C}$ e $40,5^{\circ} \mathrm{C}$ (Smith 2002).

As mucosas visíveis podem variar de coloração de acordo com vários fatores, a saber: quantidade e qualidade do sangue circulante, qualidade das trocas gasosas, presença ou não de hemoparasitos, da função hepática, da medula óssea, entre outros. De maneira geral, a coloração normal para as mucosas é rósea clara, com discretas variações. Os animais, ao nascimento, apresentam coloração rósea menos intensa (Feitosa 2008).
Em animais com hipóxia, a atividade física encontrarse-á diminuída e os animais apresentar-se-ão letárgicos, vagarosos ou incapazes de levantar-se e amamentar-se. Denota-se dificuldade respiratória (taquipnéia) e mucosas aparentes cianóticas e/ou pálidas (Benesi 1993). Em cordeiros, a hipóxia grave, durante o parto, causa morte logo após o nascimento, havendo maior risco, nos que sobrevivem, de ocorrer acidose metabólica e diminuição da capacidade de produção de calor (termogênese), o que leva a hipotermia (Heinrichs et al. 1995, Radostits 2007).

Não existem trabalhos, no Brasil, avaliando as taxas de morbidade e mortalidade em bezerros neonatos, particularmente em animais criados para produção de carne. Os zebuínos da raça Nelore (Bos indicus) são criados em muitas regiões do Brasil. No estado de São Paulo, existem muitos criatórios com animais de grande potencial genético e valor comercial. As técnicas de fertilização e de concepção dos produtos das mais variadas espécies têm evoluído exponencialmente nos últimos anos, mas a utilização de receptoras incompatíveis em relação ao tamanho dos produtos gerados tem causado vários problemas de saúde nos animais neonatos e, consequentemente, consideráveis prejuízos financeiros aos criadores, em virtude do não desenvolvimento adequado e/ou dos óbitos dos animais recém-nascidos.

Sendo assim, os objetivos deste trabalho foram determinar as variações dos parâmetros vitais e dos níveis séricos de cortisol de bezerros nelore oriundos de partos normais e laboriosos, ao nascimento e às 24 horas de vida, bem como estabelecer os índices de ocorrência de partos distócicos em vacas receptoras, de diferentes raças, submetidas à transferência de embrião.

\section{MATERIAL E MÉTODOS}

Foram acompanhados 310 bezerros da raça Nelore. Os animais eram oriundos de duas propriedades localizadas na região de Andradina/SP, que praticavam manejo extensivo convencional sob condições naturais, com controle individual do plantel e bom padrão de manejos nutricional e sanitário.

A avaliação física dos animais neonatos, realizada ao nascimento e às 24 horas, foi baseada na aferição da temperatura retal e na realização do escore Apgar et al. (1958), modificado por Born (1981), constituído pela avaliação da frequência cardíaca (FC), frequência respiratória (FR), do tônus muscular (sob estímulo de água fria na cabeça), e da coloração de mucosas, com a seguinte pontuação : 0 = ausente; 1 = diminuída; 2 = espontânea e com movimentos ativos) e resposta reflexa óculo-palpebral e interdigital ( $0=$ ausente; $1=$ um reflexo presente; 2 = dois reflexos presentes. $O$ diâmetro torácico, realizado por meio de fita métrica posicionada posteriormente aos membros anteriores, e o peso dos animais recém-nascidos, obtido com a utilização de uma balança portátil, também foram avaliados logo após o nascimento.

Os bezerros, provenientes de partos normais, permaneceram constantemente com as mães, ingerindo colostro à vontade. Os neonatos oriundos de partos distócicos, por se tratar de animais de alto valor comercial, foram alimentados com colostro ordenhado da própria mãe, por intermédio do uso de mamadeiras, sendo fornecido $10 \%$ do seu peso, distribuído em duas 
mamadas, nas seis primeiras horas após o nascimento, e entre oito e 12 horas após a primeira mamada. A higiene do umbigo era feita com produto à base de iodofórmio, fenol, ácido pícrico e diclórvós (Umbicura), uma única vez, no primeiro dia de vida.

As receptoras cruzadas, das raças Bradford/Nelore, Hereford/Nelore, Simental/Nelore, Red Angus/Nelore, Nelore e anelorados, submetidas à técnica de transferência de embrião (TE) pelo processo de fertilização in vivo (FV, 188/310) e fertilização in vitro (FIV, 122/310), eram mantidas a pasto e suplementadas com sal mineral.

As fêmeas, na fase final de gestação, eram levadas para piquete, com aproximadamente 6,2 hectares, destinados como maternidade, sendo observadas pelos funcionários, no mínimo, seis vezes ao dia, ocasiões em que se identificavam os sinais prodrômicos do parto, a ocorrência de nascimentos, abortos, e a manifestação de doenças ou de quaisquer outras alterações. O médico veterinário responsável era chamado para avaliação física e posterior intervenção, caso não ocorresse, em até uma hora após a ruptura da bolsa, a expulsão do feto.

O parto foi classificado de acordo com o grau de facilidade e/ou dificuldade para exteriorização e expulsão do concepto, a saber: um (normal); dois (distócico): $\mathrm{A}=$ pouca tração (um homem); $\mathrm{B}=$ forte tração (mais de um homem); $\mathrm{C}=$ cesariana, como descrito por Meijering (1984).

As amostras sanguíneas, utilizadas para determinação de cortisol, foram colhidas em tubos de vidro sem anticoagulante, e mantidas em temperatura ambiente para facilitar a retração do coágulo, sendo centrifugadas, a seguir, durante cinco minutos, a $3000 \mathrm{~g}$, para a obtenção do soro. O soro sanguíneo era acondicionado em Eppendorf, Axygem Scientific ${ }^{\circledR}$, com capacidade para dois $\mathrm{ml}$, e conservado em freezer a $-20^{\circ} \mathrm{C}$, em caixas de papel protegidos da luz. As determinações de cortisol foram realizadas pelo teste de Radioimunoenzimático, utilizando-se Kit comercial DPC Medlab, Coat-A-Count ${ }^{\circledR}$ Cortisol. O coeficiente de variação no inter e intra-ensaios para as dosagens de cortisol foi de $0,62 \%(48,70 \mathrm{gldL})$ para controle alto, e de $1,08 \%$ $(1,07 \mathrm{~g} / \mathrm{dL})$ para controle baixo. Em todas as dosagens, as amostras que ultrapassaram o ponto mais alto da curva foram diluídas e reanalisadas.

Depois de testadas quanto à normalidade e homogeneidade de variâncias, as variáveis FR, FC, e temperatura foram submetidas à análise de variância com medidas repetidas e teste de Tukey para comparação múltipla de médias, referentes aos tipos de partos e aos momentos de avaliação. Para comparar os tempos de parto, realizou-se análise de variância e teste de Tukey. Para comparar os tipos de partos da variável cortisol, realizou-se o teste t.

O programa de computador utilizado para análise estatística foi o SAS (Statistical Analysis System), com um nível de significância de 5\% (Zar 1999).

\section{RESULTADOS E DISCUSSÃO}

Observou-se a ocorrência de 38 partos distócicos (38/310) e 8 abortos (8/310), dos quais, 5 fetos eram oriundos da técnica de fertilização in vivo (FV), e 3 da técnica de fertilização in vitro (FIV). Pouca tração foi necessária em 14 dos 38 partos distócicos. Contudo, o auxílio foi intenso em 23 animais e, em uma vaca, realizou-se cesariana para a obtenção do concepto (Quadro 1). Em $89 \%$ do total de partos, o feto estava em uma estática fetal normal e, em $11 \%$, apresentava-se com alteração de posiciona-
Quadro 1. Número e freqüência (\%) de partos normais, distócicos e abortos em vacas receptoras cruzadas das raças Braford/Nelore, Hereford/Nelore, Simental/Nelore, RedangusiNelore, Nelore e Anelorados. Araçatuba/SP, 2007

\begin{tabular}{ccc}
\hline Partos & № & $\%$ \\
\hline Normal & 264 & 85,16 \\
Distócico (pouca tração) & 14 & 4,52 \\
Distócico (forte tração) & 23 & 7,42 \\
Distócico (cesariana) & 1 & 0,32 \\
Aborto & 8 & 2,58 \\
Total & 310 & 100,0
\end{tabular}

Quadro 2. Médias e desvios padrões de FR (mpm), FC (bpm) e temperatura $\left({ }^{\circ} \mathrm{C}\right)$ e do escore APGAR, de 290 bezerros nelore, segundo o tipo de parto e o momento de avaliação, ao nascimento e às 24 horas de vida. Araçatuba/ SP, 2007

\begin{tabular}{cccc}
\hline \multirow{2}{*}{ Variável } & \multirow{2}{*}{ Parto } & \multicolumn{2}{c}{ Momento } \\
\cline { 3 - 4 } & & Ao nascimento & Às 24 horas \\
\hline \multirow{2}{*}{$\mathrm{FR}(\overline{\mathrm{x}} \pm \mathrm{s})$} & Normal & $44,28 \pm 11,18^{\mathrm{aA}}$ & $38,33 \pm 10,39^{\mathrm{aA}}$ \\
& Distócico & $49,20 \pm 22,65^{\mathrm{aA}}$ & $42,40 \pm 13,17^{\mathrm{aA}}$ \\
$\mathrm{FC}(\overline{\mathrm{x}} \pm \mathrm{s})$ & Normal & $143,72 \pm 21,45^{\mathrm{aA}}$ & $116,72 \pm 17,68^{\mathrm{bB}}$ \\
& Distócico & $152,00 \pm 23,38^{\mathrm{aA}}$ & $132,20 \pm 18,74^{\mathrm{aB}}$ \\
Temperatura & Normal & $39,68 \pm 0,60^{\mathrm{aA}}$ & $39,47 \pm 0,22^{\mathrm{aA}}$ \\
$(\overline{\mathrm{x}} \pm \mathrm{s})$ & Distócico & $40,00 \pm 0,60^{\mathrm{aA}}$ & $39,54 \pm 0,38^{\mathrm{aB}}$ \\
Apgar & Normal & $7,72 \pm 0,75^{\mathrm{a}}$ & Não realizado \\
& Distócico & $5,40 \pm 1,17^{\mathrm{b}}$ & Não realizado \\
\hline
\end{tabular}

Médias seguidas de letras diferentes, minúsculas na coluna e maiúsculas na linha, diferem entre si $(p<0,05)$.

mento, sendo, a apresentação posterior no meio intrauterino, predominante para a maioria dos fetos.

Foi possível constatar que os partos normais tiveram, em média, período de duração de uma hora e meia, e de três horas e meia, aproximadamente, para os partos distócicos, como também observado por Meijering (1984).

Os valores médios encontrados para a FC (Quadro 2) situaram-se ligeiramente acima daqueles citados por Smith (2002), ao nascimento, e discretamente abaixo dos valores descritos por Radostits (2007). Não denotaram diferenças estatísticas com relação ao tipo de parto, ao nascimento. Contudo, as frequências cardíacas foram menores, às 24 horas, nos diferentes tipos de nascimento (Quadro 2). Jonker et al. (1996) obtiveram resultados semelhantes, já que detectaram diminuição da frequência cardíaca, em animais nascidos de partos laboriosos. $\mathrm{O}$ decréscimo da FC, entre o nascimento e as primeiras 24 h, é fisiológica, já que a elevação dos batimentos cardíacos, ao nascimento, ocorreu pela liberação de catecolaminas ocasionada pelo estresse do parto, decrescendo, gradativamente, com o passar do tempo.

De acordo com os resultados apresentados no Quadro 2, os valores médios de FR encontrados no presente trabalho encontraram-se dentro dos valores de normalidade para animais neonatos, segundo Smith (2002). Porém, quando os intervalos de duração dos partos distócicos foram levados em consideração, constataram-se menores valores de FR, à medida que o tempo da intervenção 


\begin{tabular}{|c|c|c|c|c|c|c|}
\hline \multirow[t]{2}{*}{ Tempo } & \multicolumn{3}{|c|}{ Ao nascimento } & \multicolumn{3}{|c|}{ Às $24 \mathrm{~h}$} \\
\hline & FR & $\mathrm{FC}$ & $\mathrm{T}\left({ }^{\circ} \mathrm{C}\right)$ & FR & $\mathrm{FC}$ & $\mathrm{T}\left({ }^{\circ} \mathrm{C}\right)$ \\
\hline $0-2$ horas & $70,67 \pm 23,35^{a}$ & $171,67 \pm 24,66^{a}$ & $39,80 \pm 0,36^{a}$ & $44,00 \pm 11,14^{a}$ & $122,67 \pm 6,43^{a}$ & $39,47 \pm 0,21^{a}$ \\
\hline $2-4$ horas & $41,33 \pm 5,77^{a}$ & $145,33 \pm 28,45^{a}$ & $40,03 \pm 0,68^{a}$ & $42,67 \pm 12,70^{a}$ & $144,33 \pm 26,73^{a}$ & $39,37 \pm 0,57^{a}$ \\
\hline $4-6$ horas & $39,00 \pm 22,18^{a}$ & $142,25 \pm 11,70^{a}$ & $40,13 \pm 0,79^{a}$ & $41,00 \pm 18,02^{a}$ & $130,25 \pm 17,52^{a}$ & $39,73 \pm 0,34^{a}$ \\
\hline
\end{tabular}

Médias seguidas de letras diferentes, na coluna, diferem entre $\mathrm{si}(\mathrm{p}<0,05)$.

ao parto aumentava (Quadro 3), provavelmente, em virtude da depressão do centro respiratório, ocasionada pelo maior período de tempo do feto nas vias fetais, contrariando as observações de Benesi (1993), que relatou o desenvolvimento de taquipnéia, em bezerros nascidos de partos laboriosos. Durante a fase de nascimento o animal está sujeito a um baixo suprimento de oxigênio. Desta forma, a taquipnéia também ocorreu nos neonatos nascidos de partos eutócicos, porém, de forma transitória, causada pela hipoxemia associada com o processo do nascimento e a absorção de líquido pulmonar. Os neonatos saudáveis sofrem, discreta acidose após o nascimento. Já, a taquipnéia prolongada, acompanhada de dilatação de narinas e abertura da boca para respirar (dispnéia), pode ser sugestiva de envolvimento pulmonar primário (Gardiner 1980). Apesar de não terem sido constatadas diferenças estatisticamente significativas entre as frequências respiratórias, aferidas de bezerros nascidos de partos eutócicos e laboriosos, em ambos os períodos estudados (Quadro 2), este parâmetro biológico deve ser sempre levado em consideração para os diferentes tipos de nascimentos e momentos de observação, mesmo que haja, na maioria dos casos, rápida ação dos mecanismos respiratórios de compensação, em animais com acidose metabólica (Haskins 1977, Lisboa et al. 2002).

De maneira geral, constatou-se, às 24 horas, estabilização da frequência respiratória, acompanhada de diminuição da frequência cardíaca e dos valores da temperatura retal, em animais nascidos de partos normais e distócicos, possivelmente, em virtude da melhora na condição clínica dos mesmos com o passar das horas, ocasionada pelo maior fluxo sanguíneo, pela elevação das taxas de oxigênio, e consequente diminuição dos níveis de dióxido de carbono circulantes.

Os valores médios da temperatura retal, ao nascimento e às 24 horas de vida (Quadro 2), permaneceram compreendidos dentro das faixas de variação descritas por Smith (2002) e Radostits (2007). A diferença observada, às 24 horas, entre bezerros nascidos de partos eutócicos e distócicos ocorreu, provavelmente, devido às injúrias e manipulações sofridas durante as manobras de parto e/ou ao maior grau de desidratação destes animais, diminuindo, consequentemente, a sua capacidade de eliminação de calor.

O exame das mucosas óculo-palpebrais dos animais, ao nascimento, demonstrou que 232 bezerros apresentavam mucosas com coloração rósea-clara, e 58 possuíam altera- ções de coloração, a saber: seis animais apresentavam coloração cianótica; 47 animais possuíam mucosas pálidas; quatro bezerros possuíam mucosas ictéricas (encontrandose, por meio de esfregaço sanguíneo capilar, Anaplasma sp.) e, em um animal, a tonalidade hiperêmica estava presente. Às $24 \mathrm{~h}$, quase que a totalidade dos animais exibia mucosas normocoradas. A palidez e cianose ocorrem quando a concentração de hemácias e hemoglobina encontra-se reduzida, normal, ou próxima do normal, e há oxigenação incompleta da mesma, como comumente visto nos casos de hipóxia neonatal (Radostits 2007).

A avaliação da condição física de todos os bezerros, ao nascimento, feita pelo uso do teste de Apgar, revelou que $22 \%$ (68/310) dos animais tiveram nota final de quatro pontos; $40 \%$ (126/310) receberam o total de cinco pontos; $28 \%$ (87/310) dos neonatos apresentavam-se com pontuação final de seis pontos e, por fim, 10\% (31/310) ganharam o valor máximo de oito pontos. O escore Apgar demonstrou significado estatístico $(p<0,05)$ quanto ao tipo de parto, já que os animais oriundos de partos eutócicos eram possuidores das maiores pontuações (Quadro 2). Contudo, torna-se necessário o acompanhamento dos animais durante as primeiras horas de vida, já que cerca de $90 \%$ dos animais estudados, independente do tipo de nascimento, obtiveram de baixa à moderada pontuação, colocando-os numa classificação de animais deprimidos ou débeis, caso tal escore fosse aplicado somente no momento do nascimento. Apesar de não se ter verificado diferenças estatisticamente significativas, a importância do escore Apgar ficou mais bem demonstrada quando se denotou, à medida que o tempo elevava-se para o nascimento do bezerro, o decréscimo gradativo da pontuação total média, a saber: de $6,33 \pm 1,53$, para os animais nascidos entre zero e duas horas; de $5,33 \pm 1,15$, para os partos que demoraram entre duas e quatro horas; e, finalmente, de $4,75 \pm 0,50$, para as vacas que demoraram, entre quatro e seis horas, para que ocorresse a expulsão do concepto.

Resultado relevante foi o elevado índice de animais que adoeceram nos primeiros dias de vida (226/290), ou seja, taxa de $77,93 \%$, sendo as enfermidades e/ou as alterações observadas, listadas no Quadro 4. Madruga et al. (1984), ao estudarem as causas de doenças em bezerros, no Estado de Mato Grosso do Sul, descreveram a diarréia como sinal clínico de maior frequência em bezerros de corte, tendo sido, a míase umbilical, importante causa de morbidade e mortalidade. Apesar da elevada incidência de doenças, a taxa de mortalidade foi de $3,44 \%$ 
Quadro 4. Número e freqüência (\%) de enfermidades e/ou alterações em bezerros nelores, oriundos de transferência de embriões. Araçatuba/SP, 2007

\begin{tabular}{ccc}
\hline Enfermidades & № & $\%$ \\
\hline Onfaloflebite & 50 & 22,12 \\
Miíase umbilical & 22 & 9,73 \\
Diarréia & 19 & 8,41 \\
Hérnia umbilical & 17 & 7,52 \\
Associação das enfermidades & 81 & 35,84 \\
Outras enfermidades & 37 & 16,37 \\
Total & 226 & 100
\end{tabular}

(10/290), contrapondo-se, por ser menor, as relatadas por Bull et al. (1980) e Feitosa et al. (2001). Foram observados, ainda, 12 animais natimortos, elevando a taxa de mortalidade para $7,28 \%$ (22/302). A falta de observação constante, a utilização de mão de obra sem qualificação, e a carência de cuidados básicos, foram fatores decisivos para a ocorrência da elevada morbidade dos animais neonatos utilizados no nosso trabalho.

Os valores de cortisol, no soro sanguíneo, foram de $9,85 \pm, 31 \mu \mathrm{g} / \mathrm{dL}$ e $9,02 \pm 2,83 \mu \mathrm{g} / \mathrm{dL}$, ao nascimento, e de $3,45 \pm 2,11 \mu \mathrm{g} / \mathrm{dL}$ e $4,70 \pm 4,02 \mu \mathrm{g} / \mathrm{dL}$, às 24 horas, para partos normais e distócicos, respectivamente. Não foram observadas diferenças estatísticas significativas para os níveis de cortisol em relação ao tipo de parto, discordando das considerações feitas por Stott \& Reinhard (1978), que descreveram maiores teores séricos em animais nascidos de partos eutócicos, e de Massip (1980) e Cappel (1996) que afirmaram que a distocia severa pode aumentar os níveis de cortisol em 50 a $80 \%$. Contudo, os animais nascidos de partos que demoraram entre zero e duas horas apresentavam, às 24 horas, maiores níveis séricos de cortisol $(8,04 \pm 5,67 \mu \mathrm{g} / \mathrm{dL})$ do que os nascidos entre duas e quatro $(3,68 \pm 2,39 \mu \mathrm{g} / \mathrm{dL})$, e daqueles nascidos entre quatro e seis horas $(3,40 \pm 2,36 \mu \mathrm{g} / \mathrm{dL})$. O maior tempo dispendido para o nascimento dos bezerros, associado à maior intensidade do auxílio externo nas distocias severas, foram fatores importantes para o declínio dos teores de cortisol observado neste estudo, tendo em vista a rápida metabolização do cortisol entre o início do trabalho de parto e o efetivo nascimento dos animais, na tentativa de elevar os níveis séricos de glicose, através da gliconeogênese, e manter, assim, a temperatura corpórea dos neonatos dentro dos limites fisiológicos. Desta forma, os níveis séricos de cortisol, no momento da colheita da amostra sanguínea dos animais oriundos de partos prolongados, se encontravam reduzidos ao nascimento. Bellows \& Lammoglia (2000) descreveram reduzido teor sérico de cortisol naqueles bezerros nascidos de partos distócicos que necessitaram de assistência obstétrica mais intensa.

A "Síndrome da prole grande" (large offspring syndrome) foi descrita para embriões produzidos in vitro (Hasler 1996), e é considerada uma das causas de relevância para a mortalidade perinatal (Fecteau et al. 2005). No presente trabaIho, dos 38 animais que nasceram de partos distócicos, 26 possuíam até $39 \mathrm{~kg}$ ao nascimento, sete tinham $40-49 \mathrm{~kg}$, dois pesavam $50-59 \mathrm{~kg}$, e três bezerros nasceram com peso superior a $60 \mathrm{~kg}$. Os bezerros nelores, filhos de vacas primíparas nascidos de partos distócicos, apresentavam maior peso corpóreo ao nascimento, quando comparados àqueles nascidos de partos normais (Quadro 5). Da mesma forma, constatou-se maior circunferência torácica, em bezerros oriundos de partos distócicos, do que nos nascidos de partos normais (Quadro 5).

Quadro 5. Média ( $\bar{x}$ e desvio padrão (s) da circunferência torácica e peso de bezerros nelores, ao nascimento, segundo o tipo de parto (Eutócico e Distócico) e o número de parições (Primípara e Plurípara). Araçatuba/ SP, 2008

\begin{tabular}{cccc}
\hline Variável & \multirow{2}{*}{ Parto } & \multicolumn{2}{c}{ Momento (média \pm desvio padrão) } \\
\cline { 3 - 4 } & & Primípara & Plurípara \\
\hline \multirow{2}{*}{ Tórax $(\mathrm{cm})$} & Eutócico & $73,59 \pm 4,23^{\mathrm{bB}}$ & $74,73 \pm 3,73^{\mathrm{aA}}$ \\
& Distócico & $75,95 \pm 4,10^{\mathrm{aA}}$ & $73,31 \pm 6,03^{\mathrm{aA}}$ \\
\multirow{2}{*}{ Peso $(\mathrm{kg})$} & Eutócico & $35,83 \pm 4,94^{\mathrm{bB}}$ & $37,81 \pm 5,16^{\mathrm{aA}}$ \\
& Distócico & $41,35 \pm 9,42^{\mathrm{aA}}$ & $40,43 \pm 11,26^{\mathrm{aA}}$ \\
\hline
\end{tabular}

Médias seguidas de letras diferentes, minúsculas na coluna e maiúsculas na linha, diferem entre si $(p<0,05)$.

Assim sendo, é bem provável que o peso e o tamanho do bezerro, ao nascimento, associados às características específicas das receptoras dos embriões (tamanho e número de parições da vaca, por exemplo) sejam os principais responsáveis pela ocorrência de distocias em receptoras de vacas nelores, concordando com as afirmações de Andersen et al. (1993), Farin et al. (2001), Farin et al. (2004), Fecteau et al. (2005) e Radostits (2007). Algumas receptoras ou mães de aluguel, por serem jovens e primíparas, não apresentariam, durante o período gestacional, possivelmente, desenvolvimento pélvico proporcional ao crescimento fetal.

\section{CONCLUSÕES}

Os resultados indicaram que os partos distócicos influenciam alguns dos parâmetros vitais dos animais neonatos, tais como a temperatura retal e a frequência respiratória.

A avaliação da vitalidade dos neonatos, por intermédio do teste APGAR, demonstrou, que, independente do tipo de parto, $90 \%$ dos animais nasceram com depressão variável, com pontuação entre quatro e seis.

Observou-se a ocorrência de 10\% de partos distócicos em receptoras de embriões nelores.

As principais causas de perdas de bezerros ocorreram durante o período gestacional, em virtude dos abortos e, durante a fase de periparto, pela ocorrência de doenças infecciosas.

Os teores de cortisol séricos foram maiores quanto mais demorado o trabalho de parto.

Agradecimentos.- à FAPESP (Processo 2007/55829-9), pelo apoio financeiro concedido.

\section{REFERÊNCIAS}

Andersen K.J., Brinks J.S., Lefever D.G. \& Odde K.G. 1993. The factors associated with dystocia in cattle. Vet. Med. 88:764-776. 
Apgar V., Holaday D.A., Jamev L.S., Weisbrot M. \& Berrien C. 1958. A proposal for a new method for evaluation of the newborn infant. Anesth. et Analg. 168(15):1985-1988.

Bellows R. \& Lammoglia M. 2000. Effects of severity of dystocia on cold tolerance and serum concentrations of glucose and cortisol in neonatal beef calves. Theriogenology 53(3):803-813.

Benesi F.J. 1993. Síndrome asfixia neonatal nos bezerros: importância e avaliação crítica. Arq. Esc. Med. Vet. UFBA 16(1):38-48.

Born E. 1981. Untersuchungen über den Einfluss der Schnittentbindung auf die Vitalität neugeborener Kälber. Dissertation, Tierärztliche Hochschule, Hannover. 47p.

Bull R.C., Sasser R.G. \& Olson D. 1980. Calf death losses and reproductive failure as result of maternal protein deficiency. Proc. 92th Annual Science Seminar of the California Veterinary Medical Association, Davis, CA.

Cappel T.G. 1996. An evaluation of dystocia and the endocrine response to stress in the primiparous heifer and calf. Thesis, University of Nebraska, Licoln.

Farin P.W., Grosier A.E. \& Farin C.E. 2001. Influence of in vitro systems on embryo survival and fetal development in cattle. Theriogenology 55(1):151-170.

Farin C.E., Farin P.W. \& Piedrahita J.A. 2004. Development of fetuses from in vitro-produced and cloned bovine embryos. J. Anim. Sci. 82(Suppl.):53-62.

Fecteau M.E., Palmer J.E. \& Nilkins P.A. 2005. Neonatal care of highrisck cloned and transgenic calves. Vet. Clin. North Am., Food. Anim. Pract. 21(3):637-653.

Feitosa F.L.F., Birgel E.H., Mirandola R.M.S. \& Perri S.H.V. 2001. Diagnóstico de falha de transferência de imunidade passiva em bezerros através da determinação de proteína total e de suas frações eletroforéticas, imunoglobulinas $\mathrm{G}$ e $\mathrm{M}$ e da atividade da gama glutamiltransferase no soro sangüíneo. Ciência Rural 31(2):251-255.

Feitosa F.L.F. 2008. Semiologia Veterinária: a arte do diagnóstico. $2^{\mathrm{a}}$ ed. Roca, São Paulo. 754p.

Gardiner R. 1980. Cerebral blood flow and oxidative metabolism during hypoxia and asphyxia in the new-born calf and lamb. J. Phys. 305:357376.

Haskins S.C. 1977. An overview of acid-base physiology. J. Am. Vet. Med. Assoc. 170(4):423-428.

Hasler J.F. 1996. Commercial production of in vitro derived bovine embryos. Arq. Fac. Vet. UFRGS 24(1):117-134.

Heinrichs A.J., Wells S.J. \& Losinger W.C.A.1995. A study of the use of milk replacers for dairy calves in the United States. J. Dairy Sci. 78(12):2831-2837.

Jonker F.H., Van Geijn H.P., Chan W.W., Raush W.D., Van der Wieden G.C. \& Taverne M.A. 1996. Characteristics of fetal heart rate changes during the expulsive stage of bovine parturition in relation to fetal outcome. Am. J. Vet. Res. 57(9):1373-1381.
Kasaki T.R. \& Wikse S.E. 1994. Perinatal mortality in beef herds. Vet. Clin. North Am., Food Anim. Pract. 10(1):1-185.

Kelly W. R. 1976. Diagnóstico Clínico Veterinário. Continental, México. 444p.

Lay D.C., Friend T.H., Bowers C.L., Grissom K.K. \& Efenkins O.C. 1992. A comparative physiological and behavioral study of freeze and hotiron branding using dairy cows. J. Anim. Sci. 70(4):1121-1125.

Lefcourt A.M. \& Elsasser T.H. 1995. Adrenal responses of Angus $x$ Hereford cattle to the stress of weaning. J. Anim. Sci. 73(9):26692676.

Lisboa J.A.N., Benesi F.J., Leal M.L. \& Teixeira C.M.C. 2002. Efeito da idade sobre o equilíbrio ácido básico de bezerras sadias no primeiro mês de vida. Braz. J. Vet. Res. Anim. Sci. 39(3):136-142.

Madruga C.R., Gomes R., Schenk M.A.M., Kessler R.H., Gratão G., Gales M.E., Schenk J.A.P., Andreasi M., Brachin I. \& Miguita M. 1984. Etiologia de algumas doenças de bezerros de corte no Estado de Mato Grosso do Sul. Embrapa-CNPGC, Campo Grande, MS. 27p.

Massip A. 1980. Relationship between pH, plasma cortisol and glucose concentrations in the calf at birth. Brit. Vet. J. 136(6):597-601.

Meijering A. 1984. Dystocia and stillbirth in cattle: A review of causes, relations and implications. Livest. Prod. Sci. 11:143-177.

Osinga A.1978. Endocrine aspects of bovine dystocia with special reference to estrogens. Theriogenology 10:114-166.

Peixer M.A.S., Dode M.A.M. \& Rumpf R. 2000. In vitro production of embryos- Embrapa genetic resources and biotechnology point of view. Arq. Fac. Vet. UFRGS, Supl.1:163-166.

Patterson D.J., Bellows R.A., Burferning P.J. \& Carr J.B. 1987. Occurrence of neonatal and postnatal mortality in range beef cattle. I. Calf loss incidence from birth to weaning, backward and breech presentation and effects of calf loss on subsequent pregnancy rates of dams. Theriogenology 28(5):557-571.

Radostits O.M., Gay C.C., Hinchcliff K.W. \& Constable P.E. 2007. Veterinary Medicine: A textbook of the diseases of cattle, horses, sheep, pigs and goats. $10^{\text {th }}$ ed. W.B. Saunders, London. 2065p.

Ray D.E., Hansen W.J. \& Theurer C.B. 1972. Physical stress and corticoid levels of stress. J. Anim. Sci. 34:900.

Silva R.G. \& Gondim A.G. 1971. Comparação entre as raças Sindi e Jersey e seus mestiços, relativa à tolerância ao calor na região amazônica. Pesq. Agropec. Bras. 6:37-44.

Smith B.P. 2002. Large Animal Internal Medicine. $3^{\text {rd }}$ ed. Mosby, St Louis. 1735p.

Stott G.H. \& Reinhard E.J. 1978. Adrenal function and passive immunity in the dystocial calf. J. Dairy Sci. 61(10):1457-1461.

Wood C.E. 1999. Control of parturition in ruminants. J. Reprod. Fertil. 54(Suppl.):115-126.

Zar J.H. 1999. Biostatistical Analysis. 4th ed. Prentice-Hall, New Jersey. 930p. 